\title{
Cross-cultural adaptation of the Work Role Functioning Questionnaire 2.0 to Norwegian and Danish
}

Thomas Johansen $^{\mathrm{a}, *}$, Thomas Lund ${ }^{\mathrm{b}, \mathrm{c}}$, Chris Jensen ${ }^{\mathrm{a}, \mathrm{d}}$, Anne-Mette Hedeager Momsen ${ }^{\mathrm{e}}$, Monica Eftedal $^{\mathrm{a}}$, Irene Øyeflaten ${ }^{\mathrm{a}, \mathrm{f}}$, Tore N. Braathen ${ }^{\mathrm{g}}$, Christina M. Stapelfeldt ${ }^{\mathrm{e}} \mathrm{h}$, Ben Amick III ${ }^{\mathrm{i}, \mathrm{j}}$ and Merete Labriola ${ }^{\mathrm{e}, \mathrm{h}}$

${ }^{a}$ National Advisory Unit on Occupational Rehabilitation, Rauland, Norway

${ }^{\mathrm{b}}$ Centre for Social Medicine, Frederiksberg \& Bispebjerg Hospital, Copenhagen, Denmark

${ }^{\mathrm{c}}$ Department of Public Health, Aarhus University, Aarhus, Denmark

${ }^{\mathrm{d}}$ Department of Public Health and General Practice, Norwegian University of Science and Technology,

Trondheim, Norway

${ }^{\mathrm{e}}$ DEFACTUM, Social and Health Services and Labour Market, Central Denmark Region, Aarhus, Denmark

${ }^{\mathrm{f}}$ Uni Research Health, Bergen, Norway

${ }^{\mathrm{g}}$ University College of Southeast Norway, Porsgrunn, Norway

${ }^{\mathrm{h}}$ Department of Public Health, Section of Clinical Social Medicine and Rehabilitation, Aarhus University, Aarhus, Denmark

${ }^{\mathrm{i}}$ Institute for Work and Health, Toronto, ON, Canada

${ }^{\mathrm{j}}$ Florida International University, Miami, FL, USA

Received 3 March 2017

Accepted 3 August 2017

\begin{abstract}
.
BACKGROUND: A healthy and productive working life has attracted attention owing to future employment and demographic challenges.

OBJECTIVE: The aim was to translate and adapt the Work Role Functioning Questionnaire (WRFQ) 2.0 to Norwegian and Danish.

METHODS: The WRFQ is a self-administered tool developed to identify health-related work limitations. Standardised cross-cultural adaptation procedures were followed in both countries' translation processes. Direct translation, synthesis, back translation and consolidation were carried out successfully.

RESULTS: A pre-test among 78 employees who had returned to work after sickness absence found idiomatic issues requiring reformulation in the instructions, four items in the Norwegian version, and three items in the Danish version, respectively. In the final versions, seven items were adjusted in each country. Psychometric properties were analysed for the Norwegian sample $(n=40)$ and preliminary Cronbach's alpha coefficients were satisfactory. A final consensus process was performed to achieve similar titles and introductions.

CONCLUSIONS: The WRFQ 2.0 cross-cultural adaptation to Norwegian and Danish was performed and consensus was obtained. Future validation studies will examine validity, reliability, responsiveness and differential item response. The WRFQ can be used to elucidate both individual and work environmental factors leading to a more holistic approach in work rehabilitation.
\end{abstract}

Keywords: Translation, work disability measurement, work outcome measure, work participation, work rehabilitation

\footnotetext{
*Address for correspondence: T. Johansen, $\mathrm{PhD}, \quad$ National Advisory Unit on Occupational Rehabilitation, Haddlandsvegen
} 


\section{Introduction}

The promotion of a sustainable, healthy, and productive working life has attracted significant attention owing to future employment and demographic challenges $[1,2]$. Over the next decades, OECD countries will continue to age, leading to unprecedented shares of their population being 80 years and over [1]. In Europe, the population of working age (15-64) will subsequently decline and the European Union will move from having four to only two persons between 15 and 64 for every citizen aged 65 or above [2]. Given the expected slow growth or even decline in the working age population and the ageing of the workforce, a better understanding of the impact of health on working life is relevant, and it seems fruitful to investigate the concept of work functioning. The concept reflects the continuum between the ability and the inability of the worker to meet all work demands given the current state of health taking into account a worker's transitions between sickness absence and work participation [3]. Work ability and work productivity may be constructs, which depend on and are associated with work functioning [4]. The Work Role Functioning Questionnaire (WRFQ) [5] is developed from "Work Limitations Questionnaire (WLQ)" [6] and Work Limitations-26 items (WL26) [7]. WLQ and WL-26 both measure capacity to work whilst workers are at work. Both questionnaires were developed by the same group of researchers, and share over $90 \%$ items and wording. The WLQ has four demand domains: physical, time, mentalinterpersonal and output. The WL-26 has 26-items of similar style, purpose and scoring to the WLQ. It defines the middle category on the Likert scale differently, as 'approximately half the time' [8]. The WRFQ is a generic instrument capturing both physical and mental work demands in the 21st century. The instrument can be used to evaluate workplace and work rehabilitation services aiming to improve work functioning as well as monitoring work functioning prospectively. In Norway and Denmark, no such validated instruments exist to assess healthrelated work functioning and it was chosen over other instruments because it is generic and is applicable in the general working population independent of type of work.

The WRFQ has been cross-culturally translated and adapted to Dutch [9], Brazilian Portuguese [10], Turkish [11], Canadian French [12] and Spanish [13], while validations of the WRFQ have been conducted in the Netherlands [4], Spain [14, 15] and Brazil
[10]. Thus, a cross-cultural translation study of the validated Dutch version of the instrument (WRFQ 2.0) [4] in both Norway and Denmark was initiated. The languages in these two countries are similar, and results from future projects that include the WRFQ in these two countries may be directly compared if potential discrepancies are corrected already in the translation of the instrument.

The WRFQ 2.0 consists of 22 original items and five new items added and validated in the Dutch version [4]. The WRFQ 2.0 has four subscales: 1) work scheduling and output demands, 2) physical demands, 3) mental and social demands and 4) flexibility demands $[4,5,16]$. The WRFQ is scored on a five-point Likert scale, measuring the amount of work time during the past four weeks a worker had difficulty carrying out work demands due to physical or mental challenges. This means that a worker prior to the four week recall period could have been on partial sick leave, as long as he/she had been working for the past four weeks. The response options are: 0 difficult all of the time, 1 - difficult most of the time, 2 - difficult half of the time, 3 - difficult some of the time, 4 - difficult none of the time. The option 'does not apply to my job' is also available.

The aim of the present study was to cross-culturally translate and adapt the English version of the Dutch WRFQ 2.0 to Norwegian and Danish. Future application of the instrument is assumed to improve assessment of health-related work functioning involving the workplace and work rehabilitation services in Norway and Denmark, and facilitate Norwegian and Danish participation in future cross-national data comparisons on work functioning.

\section{Methods}

\subsection{Cross-cultural adaptation}

Standardised cross-cultural adaptation guidelines proposed by Beaton et al. [17] were followed in the translation processes and described below.

\subsubsection{Forward translation}

Four researchers in each country performed the initial forward translation. The professions of the researchers in both countries were multidisciplinary. In the Norwegian group, three of the researchers had prior experience in translating questionnaires. One translator did not have prior knowledge about the WRFQ concept. In Denmark, two researcher had 
prior knowledge about the WRFQ concept. Previously, seven researchers had experience in translating questionnaires [18].

\subsubsection{Synthesis of the translations}

A synthesis of the translations was performed by the four researchers in Norway and Denmark resulting in one common translation. A written report was produced documenting any discrepancies between the researchers and how the issues were resolved.

\subsubsection{Back translation}

A professional translator, one in each country, translated the synthesised version back into English. The translator was blind to the WRFQ concept and had no medical background. Discrepancies between the WRFQ 2.0 and the translated versions were discussed between the four researchers in each country and the translation was adjusted if necessary. The back translation facilitates the examination of whether the translation led to semantic or conceptual differences from the original.

\subsubsection{Expert committee}

The expert committee consisted of the researchers from both countries who conducted the forward translation. Three meetings were held in person in addition to e-mail exchanges. The expert committee went through all translated versions and forward and backward translation discrepancies were identified and discussed. The translators responsible for the back translation and the original questionnaire developers were also consulted. Consensus was reached and lingual adaptations were performed resulting in a prefinal questionnaire to be pre-tested. A written report was produced outlining how any translation issues were resolved.

\subsubsection{Pre-test of pre-final questionnaires}

The pre-final version of the questionnaire was administered to 38 participants in Denmark and 40 participants in Norway. Inclusion criteria constituted being able to read and understand the questionnaire in Danish or Norwegian and being 18-67 years of age. In Norway, the participants were recruited from two work rehabilitation centres and a delivery business company and in Denmark they were recruited from the Municipality of Aarhus. A background questionnaire and interview guide were developed and used in the pre-test [19]. Key questions targeted the layout, time to completion, instructions, wording/language, missing aspects, question clarity, provocative or sensitive questions and general opinion. After completion, participants provided either oral or written feedback about comprehensibility, completeness, acceptability, relevance and answerability. This included whether instructions, questionnaire items and responses where applicable. The researchers conducting the forward translation discussed the comments from the participants and consensus was reached on any changes made to obtain the final translated questionnaire versions.

\subsubsection{Final comparison of translated versions}

Two researchers from both Norway and Denmark, part of the expert committee, appraised and compared the translated versions. The aim was to agree on a similar title and introductory text and appraise the wording of each item. Based on consensus, adjustments were made to the Norwegian and the Danish questionnaire items where necessary (Table 1).

\subsection{Psychometric properties of pre-final questionnaire}

For the Norwegian participants $(n=40)$, psychometric data from the pre-final version were examined for mean work functioning score, floor and ceiling effects and missing items. The response option 'does not apply to my job' was set to missing [5]. Background characteristics of the participants were also collected. The face and content validity of the scale was evaluated by the expert committee throughout the translation process also taking into consideration the comments given by the participants during the pretest. Reliability measures included an assessment of the internal consistency of each subscale assessing the degree to which the individual items are correlated with each other, using the Cronbach's alpha coefficient. By convention, scores between 0.75-0.95 suggest that all the items measure the same constructs [20]. The range of item to subscale correlations was also calculated to evaluate the item's ability to discriminate between participants' work functioning. Correlations above 0.30 indicate sufficient discriminant ability [21].

\subsection{Ethics}

Approval from the Norwegian and Danish Health Research Ethics Committees was not required to conduct this study, however all participants provided written informed consent prior to participation. 
Table 1

The WRFQ's 2.0 instructions, title, translation, pre-test and adjustments based on consensus. [Items marked: * Difficult to translate; + Adapted after pre-test; \# adjusted at final comparison of pre-final version]

WRFQ 2.0
Questionnaire title
Questionnaire instructions
Work scheduling and output demands
1. Get going easily at the beginning of the workday
2. Start on your job as soon as you arrived at work
3. Do your work without stopping to take extra breaks
or rests
4. Stick to a routine or schedule
5. Work fast enough
6. Finish work on time
7. Do your work without making mistakes
8. Satisfy the people who judge your work
9. Feel a sense of accomplishment in your work
10. Feel you have done what you are capable of doing

\section{Physical demands}

11. Lift, carry, or move objects at work weighing more than 10 pounds

12. Sit, stand, or stay in one position for longer than $15 \mathrm{~min}$. while working

13. Repeat the same motions over and over again while working

14. Bend, twist, or reach while working

15. Use hand-held tools or equipment (for example, a phone, pen, keyboard, computer mouse, drill, hairdryer or sander)

\section{Mental and social demands}

16. Keep your mind on your work

17. Do work carefully

18. Concentrate on your work

19. Work without losing your train of thought

20. Easily read or use your eyes when working

21. Speak with people in-person, in meetings or on the phone

22. Control your temper around people when working

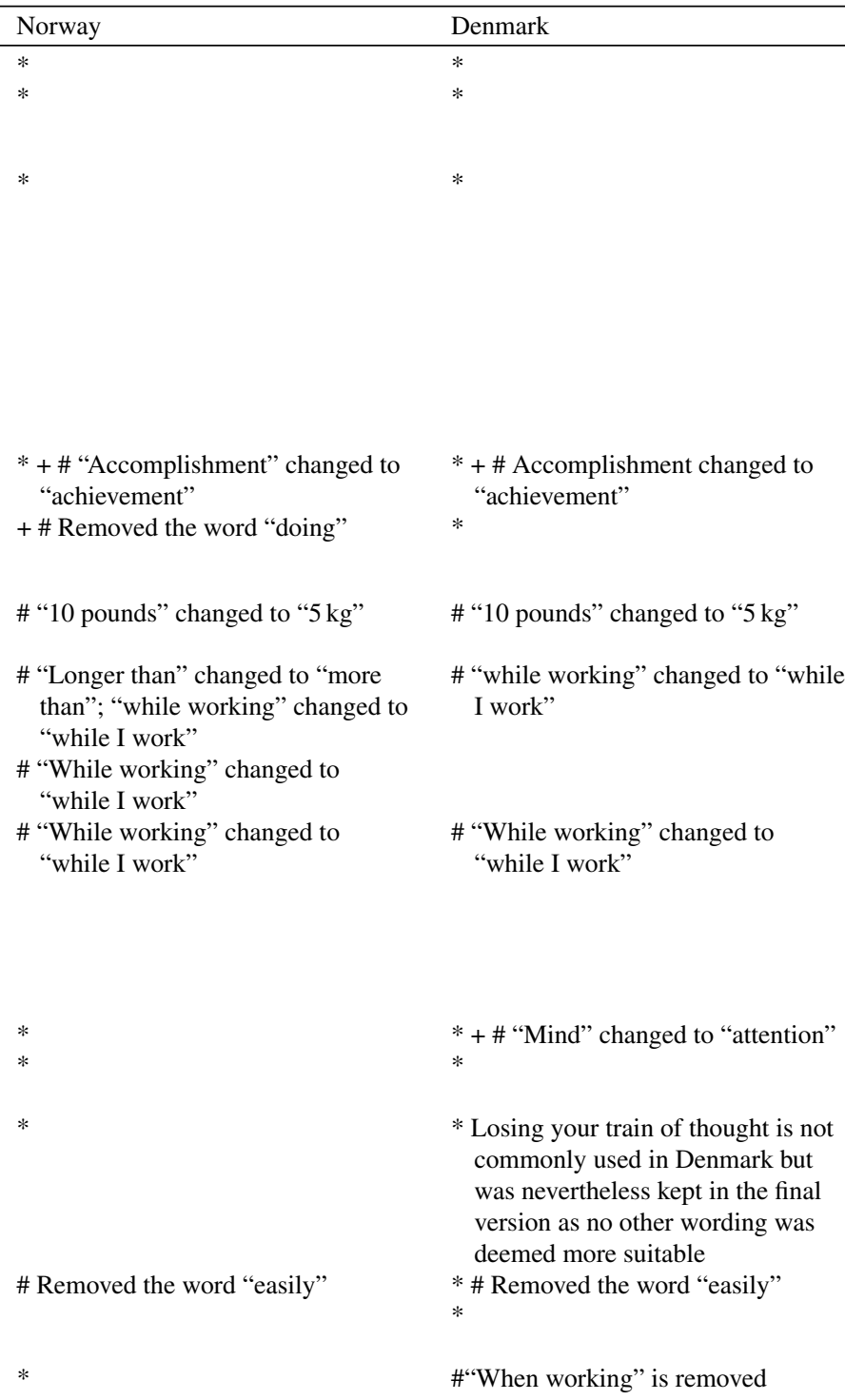

* * *

* + \# "Accomplishment" changed to "achievement"

+ \# Removed the word "doing"

\# "10 pounds" changed to " $5 \mathrm{~kg}$ "

\# "Longer than" changed to "more than"; "while working" changed to "while I work"

\# "While working" changed to

"while I work"

\# "While working" changed to

"while I work"

Denmark

*

* + \# Accomplishment changed to "achievement"

$*$ I work"

\# "While working" changed to "while I work"

\# Removed the word "easily"

* commonly used in Denmark but was nevertheless kept in the final version as no other wording was deemed more suitable

\section{Flexibility demands}

23. Set priorities in my work

24. Handle changes in my work

25. Process incoming information, for example e-mails, + "Process" changed to "take care of" in time

26. Perform multiple tasks at the same time

27. Be proactive, show initiative in my work

\section{Results}

During the WRFQ 2.0 translation, the expert committee encountered challenges regarding phrases and ambiguous wording. The back translations were com- pared for inconsistencies and resolved as follows by the expert committee. The instructions in the back translations focused too much on work tasks rather than difficulties in the amount of time handling work tasks. In the pre-final questionnaire the instructions 
were modified and made more explicit, also consulting the original version, to highlight that participants should assess the amount of time they have difficulties handling certain work tasks due to physical and mental problems and "time" was changed to "working time" and "physical health or emotional problems" was changed to "physical and mental health". The title of the questionnaire in the WRFQ 2.0 version "Work Role Functioning" was translated to "Functioning at work" as work role functioning is difficult to translate into Norwegian and Danish.

Most participants found no difficulty understanding the majority of the items. In particular, items 1 , $9,16,17$ and 19 , were revised to rectify idiomatic equivalence and semantic inconsistencies between the original and the Norwegian and Danish version. For item 11, "10 pounds" was replaced with "5 kilograms". Regarding readability, the wording "I found it difficult to..." located in column one above the first item seemed difficult to interpret for the participants. The wording was changed to "During working time I have..." (Norway) and "During working time it is difficult to..." (Denmark). At the final comparison in the expert committee, seven items were adjusted in the Norwegian and Danish versions (Table 1). The title and instructions were also harmonised as far as possible at this stage. Based on consensus, adjustments were made where necessary and the final versions of the Norwegian and Danish WRFQ 2.0 were developed. The Danish version of the WRFQ2.0 can be downloaded here and the Norwegian version here.

\subsection{Pre-test evaluation and psychometric properties}

The pre-final version of the questionnaire was administered to a subset of 40 individuals who had been on sick leave between 1 and 52 weeks and were back in part or full time work at the time of participation (Table 2).

The participants indicated high work functioning in all subscales (Table 3). The proportion of participants using the response category 'not applicable to my job' or assigned as missing items was $<15 \%$ for all subscales. The items most frequently assigned 'not applicable to my job' were items $11(n=6$; lift, carry, or move objects at work weighing more than 5 kilograms), 13 ( $n=10$; repeat the same motions over and over again while working), 15 ( $n=7$; use hand held tools or equipment) and 25 ( $n=8$; process incoming information, for example e-mails, in time). There
Table 2

Background characteristics of Norwegian participants $(n=40)$

\begin{tabular}{lc}
\hline Variable & \\
\hline Female : male, N (\%) & $28: 12$ \\
& $(70 \%: 30 \%)$ \\
Age in years, mean (SD) & $46.7(8.8)$ \\
Job type, N (\%) & \\
Manual & $6(15 \%)$ \\
Non-manual & $15(37.5 \%)$ \\
Mixed & $19(47.5 \%)$ \\
Education, N (\%) & \\
Low & $6(15 \%)$ \\
Middle & $11(27.5 \%)$ \\
High & $23(57.5 \%)$ \\
Years in employment, mean (SD) & $24.5(9.7)$ \\
Sick leave past 12 months in weeks (mean, SD) & $18.9(17.9)$ \\
Motivation to work, N (\%) & \\
Very & $34(85 \%)$ \\
Uncertain & $4(10 \%)$ \\
Little & $2(5 \%)$ \\
Work and benefit status, N (\%) & \\
Working full time & $18(45 \%)$ \\
Working part time & $18(45 \%)$ \\
Combination partial sick leave and work & $4(10 \%)$ \\
Work-related health complaints, N (\%) & \\
Musculoskeletal & $19(47.5 \%)$ \\
Psychological & $10(25 \%)$ \\
Musculoskeletal and psychological & $7(17.5 \%)$ \\
None & $4(10 \%)$ \\
\hline
\end{tabular}

were no individuals scoring 'difficult all of the time' on any of the subscales. In the other end of the scale, the percentage of participants obtaining the maximum score (never limited) varied from 5\% (mental and social demands) to $15 \%$ (flexibility demands), thus, scores at ceiling did not exceeded the $15 \%$ norm on any of the subscales [20].

The Cronbach's alpha coefficients for each subscale were all in the region of $>0.80$. The range of item to subscale correlations was all above 0.30 apart from items in the subscale 'mental and social demands'.

\section{Discussion}

The WRFQ 2.0 assesses a worker's difficulties in meeting work demands, due to physical and mental challenges. Creating as far as possible identical versions of the instrument in different countries is empirically useful because it facilitates Norwegian and Danish participation in cross-national comparisons on work functioning. Norwegian and Danish both belong to the North-Germanic languages and are historically linked, but the linguistics have evolved differently. The main differences are found in pronunciation and in the sound system [22]. Thus, a 
Table 3

Scale results and Cronbach's alpha coefficients of the pre-final version of the WRFQ ( $n=40$, Norwegian sample)

\begin{tabular}{lcccccrr}
\hline Subscale & $\begin{array}{c}\text { Number of } \\
\text { items }\end{array}$ & $\begin{array}{c}\text { Mean } \\
\text { (SD) }\end{array}$ & $\begin{array}{c}\text { Missing/“not } \\
\text { appl' (\%) }\end{array}$ & $\begin{array}{c}\% \\
\text { floor }\end{array}$ & $\begin{array}{c}\% \\
\text { ceiling }\end{array}$ & $\begin{array}{c}\text { Cronbach's } \\
\text { alpha }\end{array}$ & $\begin{array}{c}\text { Range of item } \\
\text { to subscale } \\
\text { correlation }\end{array}$ \\
\hline Work scheduling and output demands & 10 & $75.4(26.1)$ & 1.3 & 0 & 7.5 & 0.87 & $0.35-0.76$ \\
Physical demands & 5 & $76.9(26.1)$ & 15.0 & 0 & 7.5 & 0.79 & $0.39-0.80$ \\
Mental and social demands & 7 & $77.3(26.0)$ & 1.8 & 0 & 5 & 0.80 & $0.21-0.83$ \\
Flexibility demands & 5 & $75.8(19.4)$ & 6.0 & 0 & 15 & 0.85 & $0.59-0.79$ \\
Total score & 27 & $76.1(26.0)$ & 4.8 & 0 & 0 & 0.90 & $-0.20-0.85$ \\
\hline
\end{tabular}

direct comparison of the two versions seems sensible, both in terms of specific words and sentence construction. After completing the cross-cultural adaptation to Norwegian and Danish a direct comparison resulted in several changes to reduce discrepancies to a minimum.

Due to possible cross-cultural differences in the wording of items it is important to follow rigorous translation, pre-test and validation procedures prior to administering the WRFQ in clinical and work settings. The procedure for cross-cultural adaptation in the current study was based on Beaton et al. [17]. Other adaptation processes have been suggested $[23,24]$. However, the method described by Beaton and colleagues was chosen in the current study as this has been used in all countries cross-culturally adapting the WRFQ so far.

The translation process revealed similar difficulties as encountered in the other countries' translations. Notably, several countries found it necessary to change the questionnaire instructions $[9,10,12,13]$ possibly due to a lack of clarity in the original version and not related to ambiguous forward or backward translations. The instructions were modified in the Norwegian and Danish versions to make it explicit that the issue revolved around working time related to physical and mental health challenges. Items 1 (item 2 in the original version), 10 (item 12), 20 (item 24) and 22 (item 26) proved difficult to translate and adapt in the Norwegian and Danish versions as well as in the Dutch version [9]. Items 1 and 22 also seemed difficult to translate in the Brazilian Portuguese [10], Canadian French [12], and Spanish spoken in Spain [13] versions.

The participants scored on average in the upper quarter in all subscales on the WRFQ 2.0, indicating very good work functioning. High work functioning scores have also been reported from pre-testing in the Netherlands [9], Brazil [10], Canada [12], and Spain [13] as well as in a recent validation study in the Netherlands [4]. This may indicate that the instrument's discriminant validity is not optimal. Content validity was good as ceiling effects did not exceed the $15 \%$ criterion in all subscales [20]. The internal consistency was satisfactory across all subscales.

The pre-test seemed to reveal that the final version of the WRFQ may at this stage be considered semantically and conceptually equivalent to the WRFQ 2.0 version, confirming an aspect of content validity [25]. This is supported by the fact that the level of 'not applicable to my job' and missing responses did not exceed the recommended $20 \%$ on any of the subscales [26].

The aim of work rehabilitation and workplace services is often to assess improvements in functioning related to work and daily life, and it is argued that the application of the WRFQ will make these assessment more reliable and precise [4]. Thus, the WRFQ can be used to elucidate both individual and work environmental factors leading to a more comprehensive analysis of work functioning in people with short and long term as well as permanent disabilities. The quality and effect of work rehabilitation and workplace services may therefore depend on better descriptions and assessments of work functioning.

\section{Limitation}

This study is a first step towards a full validation of the WRFQ 2.0 in Denmark and Norway and hence the generalisability of the findings are limited. Generally, the low number of participants recruited in pre-tests, around 30 to 40 individuals, may result in selection effects whereby pre-test groups are too homogeneous. However, the questionnaire is intended to be used in the working populations and ceiling effects may be expected [4].

\section{Conclusion}

Future research involving the WRFQ 2.0 in Norway and Denmark can directly be compared, if 
potential discrepancies are corrected already in the translation of the instrument. The cross-cultural adaptation was performed satisfactorily and provided useful insights into how the participants and the expert committees interpreted the WRFQ 2.0 items. The next studies will examine validity, reliability, responsiveness and differential item response following the Consensus-based Standards for the selection of health Measurement Instruments (COSMIN) checklist [27]. Using the COSMIN standardised checklist when evaluating the methodological quality of WRFQ 2.0's measurement properties, will ensure that all important design aspects and statistical methods will be clearly reported across the two countries. It is argued that the WRFQ is a promising tool adapted for work in the 21 st century, targeting both individual and work environment factors leading to better assessments of work functioning.

\section{Acknowledgments}

We are grateful to all participants who kindly took their time in answering and giving feedback on the questionnaire. Thank you to Frisk Bris, Langesund, Telemark Distribusjon, Skien and the Occupational Rehabilitation Centre, Rauland in Norway.

\section{Conflict of interest}

The authors report no conflict of interest. The Danish Working Environment Research Fund funded the Danish part of this study (20-2013-09).

\section{References}

[1] Help Wanted? Providing and Paying for Long-Term Care. OECD; 2011.

[2] European Commission. Europe's demographic future: Facts and figures on challenges and opportunities. DirectorateGeneral for Employment, Social Affairs and Equal Opportunities Unit E.1; 2007.

[3] Amick III BC, Gimeno D. Measuring work outcomes with a focus on health-related work productivity loss. In: Wittink $\mathrm{H}$, Carr D, editors. Pain management: Evidence, outcomes, and quality of life: A sourcebook. Amsterdam: Elsevier; 2008. pp. 329-43.

[4] Abma FI, van dK, Bültmann U. The work role functioning questionnaire 2.0 (Dutch version): Examination of its reliability, validity and responsiveness in the general working population. J Occup Rehabil. 2013;23(1):135-47.

[5] Amick III BC, Lerner D, Rogers WH, Rooney T, Katz JN. A review of health-related work outcome measures and their uses, and recommended measures. Spine. 2000;25 (24):3152-60.

[6] Lerner D, Amick III BC, Rogers WH, Malspeis S, Bungay $\mathrm{K}$, Cynn D. The work limitations questionnaire. Med Care. 2001;39(1):72-85.

[7] Lerner DJ, Amick III BC, Malspeis S, Rogers WH. A national survey of health-related work limitations among employed persons in the United States. Disabil Rehabil. 2000;22:225-32.

[8] Grimmer-Somers K, Vipond N, Kumar S, Hall G. A review and critique of assessment instruments for patients with persistent pain. J Pain Res. 2009;2:21-47.

[9] Abma FI, Amick III BC, Brouwer S, van der Klink JJ, Bültmann U. The cross-cultural adaptation of the work role functioning questionnaire to Dutch. Work. 2012;43(2): 203-10.

[10] Gallasch CH, Alexandre NM, Amick III BC. Cross-cultural adaptation, reliability, and validity of the work role functioning questionnaire to Brazilian Portuguese. J Occup Rehabil. 2007;17(4):701-11

[11] Irmak A, Bumin G, Irmak R. The cross-cultural adaptation of the work role functioning questionnaire to Turkish. HCI International. Communication in Computer and Information Science. 2001;173:218-22.

[12] Durand MJ, Vachon B, Hong QN, Imbeau D, Amick III $\mathrm{BC}$, Loisel P. The cross-cultural adaptation of the Work Role Functioning Questionnaire in Canadian French. Int J Rehabil Res. 2004;27(4):261-68.

[13] Ramada JM, Serra C, Amick III BC, Castano JR, Delclos GL. Cross-cultural adaptation of the Work Role Functioning Questionnaire to Spanish spoken in Spain. J Occup Rehabil. 2013;23(4):566-75.

[14] Ramada JM, Serra C, Amick III BC, Abma FI, Castano JR, Pidemunt G, Bültmann U, Delclos GL. Reliability and validity of the work role functioning questionnaire (Spanish Version). J Occup Rehabil. 2014;24(4):640-49.

[15] Ramada JM, Delclos GL, Amick III BC, Abma FI, Pidemunt G, Castano JR, Bültmann U, Serra C. Responsiveness of the Work Role Functioning Questionnaire (Spanish version) in a general working population. J Occup Environ Med. 2014;56(2):189-94.

[16] Abma FI, Bültmann U, Varekamp I, van der Klink JJ. Workers with health problems: Three perspectives on functioning at work. Disabil Rehabil. 2013;35(1):20-26.

[17] Beaton DE, Bombardier C, Guillemin F, Ferraz MB. Guidelines for the process of cross-cultural adaptation of self-report measures. Spine (Phila Pa 1976). 2000;25 (24):3186-91.

[18] Momsen AM, Rosbjerg R, Stapelfeldt CM, Lund T, Jensen C, Johansen T, Nielsen CV, Labriola M. Cross-cultural adaptation and validation of the Danish version of the 19-item return-to-work self-efficacy (RTWSE-19) questionnaire. Scand J Work Environ Health. 2016;42(4):338-45.

[19] Willis GB. Developing standard cognitive probes. In: Willis GB, editor. Cognitive interviewing. California: Thousands Oaks; 2005. pp. 66-87.

[20] Terwee CB, Bot SD, de Boer MR, van der Windt DA, Knol DL, Dekker J, Bouter LM, de Vet HC. Quality criteria were proposed for measurement properties of health status questionnaires. J Clin Epidemiol. 2007;60(1):34-42.

[21] Nunnally JC, Bernstein IH. Psychometric Theory. 3rd ed. New York: McGraw-Hill; 1994.

[22] Hovdhaugen E, Karlsson F, Henriksen C, Sigurd B. The history of linguistics in the Nordic countries. Helsinki: Socieetas Scientiarum Fennica; 2000. 
[23] Forsyth BH, Kudela MS, Levin K, Lawrence D, Willis GB. Methods for translating an English-language survey questionnaire on tobaacco use into Mandarin, Cantones, Korean, and Vietnamese. Field Methods. 2007;19(3):264-83.

[24] World Health Organization. Process of translation and adaptation of instruments. 2011.

[25] Eremenco SL, Cella D, Arnold BJ. A comprehensive method for the translation and cross-cultural validation of health status questionnaires. Eval Health Prof. 2005;28: $212-32$.
[26] Amick III BC, Habeck RV, Ossmann J, Fossel AH, Keller R, Katz JN. Predictors of successful work role functioning after carpal tunnel release surgery. J Occup Environ Med. 2004;46(5):490-500.

[27] Mokkink LB, Terwee CB, Patrick DL, Alonso J, Stratford PW, Knol DL, Bouter LM, de Vet HC. The COSMIN study reached international consensus on taxonomy, terminology, and definitions of measurement properties for health-related patient-reported outcomes. J Clin Epidemiol. 2010;63(7):737-45. 